\title{
Information Systems: The Changing Scenario of Concepts, Practice and Importance
}

\author{
P. K. Paul ${ }^{1}$, P. S. Aithal ${ }^{2}$, R. Saavedra ${ }^{3}$, R.R. Sinha ${ }^{4}$ B. Aremu ${ }^{5}$, S. Mewada ${ }^{6}$ \\ ${ }_{1}$ Executive Director, MCIS, Department of CIS, Information Scientist (Offg.), Raiganj University, India. \\ 2Vice Chancellor, Srinivas University, Karnataka, India. \\ ${ }^{3}$ Director \& Chair, International Inter-University Programs, Azteca University, México. \\ ${ }^{4}$ Pro Vice Chancellor (Asian Region), Commonwealth Vocational University, Tonga. \\ 5Vice Chancellor, Crown University, Intl. Chartered Inc. (CUICI) Argentina Campus, South America. \\ 6President, International Scientific Organization for the Science, Engineering and Technology, India.
}

\begin{abstract}
Information is very important and required in almost all areas and fields. It is close to some of the areas viz. Data, Content and Knowledge. The system is also another concept that deals with the group of interrelated and connected entities, objects, tools, or facets. In other words, combinations of some subsystems are called Systems. Therefore, Systems in respect of the Information is called Information Systems. Information Systems is the way, tools, connected entities that are dedicated or responsible for the information related activities ranging from the collection, selection, organization, processing, management and dissemination. There are different contexts regarding Information Systems, in some contexts, it is also the electronic systems dedicated to information management and delivery to the organizations, institutions. In some contexts, it is the Computational way to preserve and deliver content and information. Information Systems in another context are the apex controlling mechanism of some of the divisional information systems such as Executive Information Systems, Decision Support Systems, etc. which helps in Information related activities to the organizations. Even Information System is also considered as a branch or field of study internationally. This paper is a theoretical one and mentioned the aspects of systems including their foundations, applications of systems, information systems including their foundation, types, nature, and emerging characteristics. The paper also highlights the academic availability and potentiality of Information Systems.
\end{abstract}

Keywords: Information, Information Systems, Computing, Information Infrastructure, Digitalization, Academic

\section{Introduction}

The term 'system' comes from the Latin word Systema. It is the concept of combination, parts, members, subsystems, composition. It is the process of interrelated entities and that are unified as a whole. Systems may also surround and influenced by the environment, structure. The system is also considered as a study of systems theory or systems studies. Systems can also be natural systems or human systems, open or closed systems, system processes, and system models, etc. Therefore, System can be anything and associated with any tools, products, or concerns (refer Fig: 1 for details). Systems can be applied in diverse areas and fields viz. Computing or Computer Science, Information Science, Engineering, Physics, Human 
Anatomy and Body, Strategic System, Logical Systems, Environment, Social and Society, Energy, Mechanics, etc [1], [7], [18]. Traditionally Information Systems is concerned with the information related subsystem composition and computational systems viz. -

- Software

- Hardware

- Data

- Procedure

- People

- Feedback

Information Systems in computational context and emerging context deals with various other technologies such as Data warehousing, IT Systems, Global Information Systems, Enterprise Systems, Geographic Information Systems, Global Information Systems, etc. Information Systems even also consider a field of study in many countries and considered as a field concentrated on IT applications in business, management, and the commercial world [3], [4],[12].

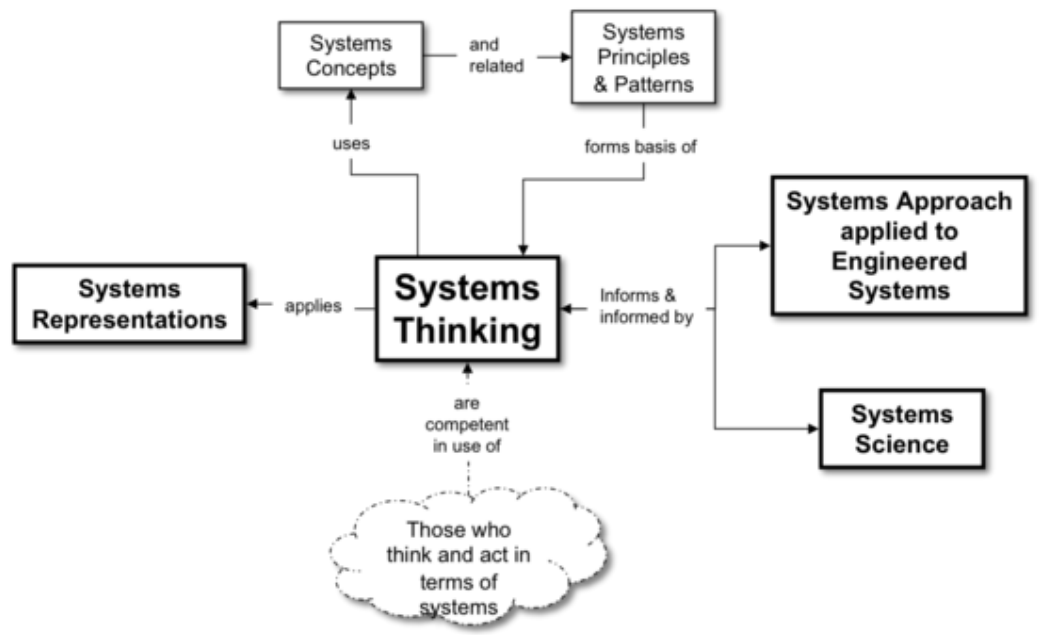

Fig: 1-Systems and whole facets at a glance

\section{Objective}

The current paper entitled 'Information Systems: The Changing Scenario of Concepts, Practice and Scenario' deals with the following aim and objectives-

- To learn about the basics of Systems including features, components and foundation in a brief manner.

- To know about the basics of the Information Systems with reference to the various thoughts.

- To learn about the basics of traditional and emerging components in Information Systems with a suitable example.

- To know about the related and allied concepts and fields of Information Systems and changing scenarios.

\section{Systems and Foundation}

System is an important concept and applicable in different fields and areas where parts, process, subfields and components consider as important and valuable and such as- 


\section{Environment-}

Environment can be considered as an important example of systems in which different things and facets are associated. In other words, various components made the environment and these are growing. The prime examples are Water parts, lands, humans, animals, forestry, etc and these are connected together [6], [21].

\section{Natural Systems and Human Made Systems-}

There are natural systems which are connected and parts of Natural Systems viz. forest, plane land, disserts, mountains, forests, etc. all these are subpart and makes natural systems; whereas many things are human made based and among these important are artificial islands, forests, valley, etc.

\section{Health Systems-}

Health System is also very important and considers as important example subsystem. As far as the Human body is concerned important are respiratory systems, digestive systems, nervous systems, muscular systems, reproductive systems, etc. As far as the overall health system is concerned important are clinical and health units, technology and systems, management systems, Patients and HR Systems, Financial Systems, and so on.

\section{Open and Closed Systems-}

Open and Closed Systems are very important and required in different sorts and areas and these are prime examples of systems.

\section{Engineering Systems-}

Engineering is a big thing and responsible for doing different activities with the help of tools, techniques, procedures and ways. Engineering only possible joint efforts of some subsystems. Further, it can be considered as the action of working artfully bringing something about. There are soft and hardcore engineering systems (Refer Fig: 2) [2], [10], [19].

\section{Computer Systems-}

Computer is an electronic device and connected with different kinds of subsystems viz. Arithmetic and Logic Unit, Central Processing Units, etc. and such builds the Input Systems and Output Systems of the Computer (refer Fig: 2).

\section{Societal Systems-}

Society is a big part in Environmental and ecological systems. There are different kinds of part and subsystems are existing societal systems including humans, community, town and rural areas, and so on. All these are connected to each other. 


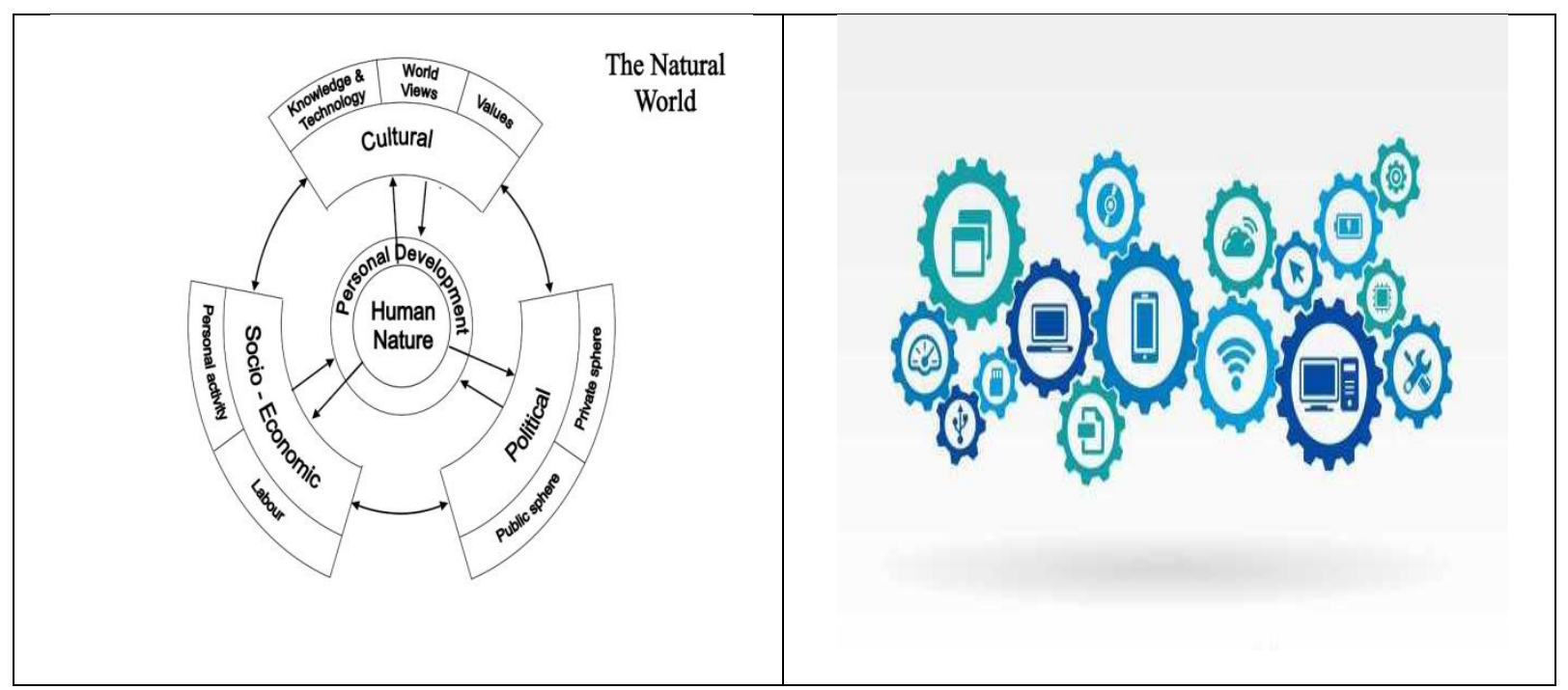

Fig:2 Systems in Natural System and Computing world

\section{Cultural Systems-}

Culture is an important part of the Societal System and there are different subsystems that make cultural systems.

\section{System Model and Architecture-}

System Model and architecture is very important to build any subsystem and towards reaching complete systems. System modeling is a basic principle in the field of engineering and also in social sciences.

\section{Applications of the Systems}

The applications of the Systems are rising and gradually applicable in diverse fields and these include the physical systems, biological systems, social systems, etc. As far as Computing and Science, Technology is concerned with some of the major and notable application areas which include-

\section{In Computer and Information Science}

Systems are very important and valuable in the field of Computer Science, Information Science, Information Technology and other allied sciences which are responsible for designing and developing information mechanisms and information infrastructure. There are hardware systems and software systems, operating system is a prime example of this (refer Fig:3) consider as important [5], [18], [21]. 


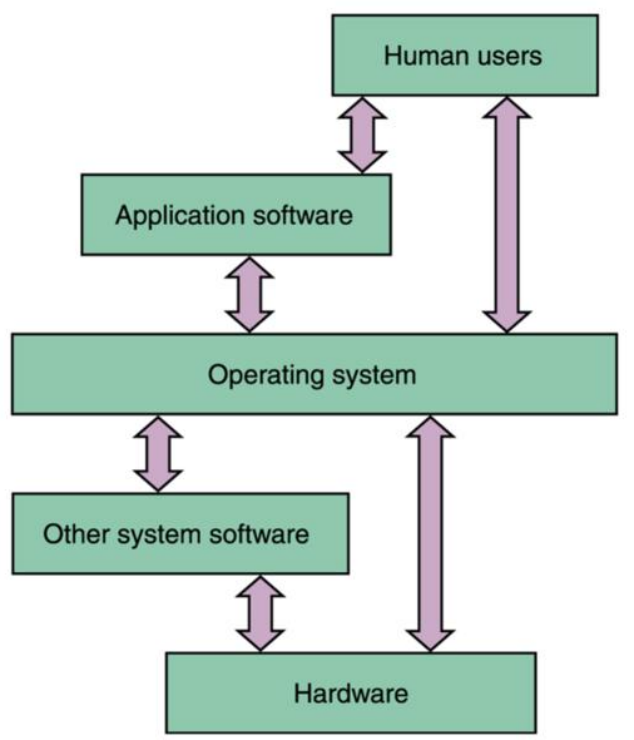

Fig:3 Systems example in Operating Systems

But other areas of Computer and Information Science can be considered as valuable viz.-

- Database Systems

- Multimedia Systems

- Networking Systems

- Communication Systems, etc.

Due to the importance of the same and these subsystems the field Computer is also called as Computer Systems, Computer and Information Systems, in traditional Information Sciences Library Systems, traditional Information Systems can be treated as important in System.

\section{In Engineering, Technology and Physics}

Systems is an important concept in different aspects and areas of Engineering and Technological development and among the notable and important concepts of systems important are-

- Physical Systems

- Engineering Systems

- Systems Engineering etc.

Engineering also has the concept of a system that is dedicated to combining different parts and interactions between parts of a complex project. The study of planning, designing, implementing, maintaining, etc. are called System Engineering

\section{In social and cognitive sciences and management}

In Social Science and Cognitive Science System consider as an important part, there are various aspects within this viz. Human Health, Brain System, Operation Research, etc. In Management Science also the system is an important and valuable facet viz. Organizational development, System thinking, etc. 


\section{Information System: Foundations}

Information Systems consist of the information and systems both and before moving in-depth regarding the Information Systems, let's know about the Information, as here already about the Systems are elaborated [16].

Information term first came into existence in the USA, as an alternative term for documentation. This word 'information' conveys knowledge, message, understanding, data, interpretation, etc. It is treated as an aggregate of statements or facts or figures which are conceptually (by way of reasoning, logic, ideas, or any other mental mode of operation) interrelated'-Hoffman. And thus, it is clear that information is a collection or we can say the accumulation of statements, facts, and figures ideas, and related aspects whatever it may be and that are organized processed in a systematic and scientific manner. And virtually systematic manner can be done or processed or possible through/by way of reasoning, logic, ideas, interpretation, etc.

"information is piecemeal, fragmented, particular whereas knowledge is structural coherent and universal; information is timely transitory perhaps even ephemeral whereas knowledge is of enduring significance; information is the flow of message, whereas knowledge is a stock, largely resulting from the flow, in the sense that the input of information may affect the stock of knowledge by adding to it, restructuring it or changing it in any way" (According to Mach lap). Information Systems is a process, systems and way in respect of information-related activities ranging from collection, selection, processing, management, delivery. It is the set of components and products in the digitalization of the information. It is dedicated to the collection, storing and delivery of Information related tools, techniques and technologies [14], [20]. In other words, Information System is a process of developing information repositories and digital systems for a wide range of stakeholders viz. -

- Organizations.

- Institutions.

- Government.

- Information related foundations and establishments.

- Individuals etc.

Information Systems and roles are changing day by day as it is a combination of several subsystems dedicated to the information activities therefore it is named 'Information Systems'. Initially, it was the concept of applications in IT and Computing in the IT-related organization but gradually it becomes a field of practice in other organizations. Information Systems is responsible for the planning, designing, development, management of IT and Information Infrastructure. Since it is an integrated system and dedicated to information solutions therefore it is helpful in the delivery of information and technological support to the client and users, organizational manpower, staff, administration, suppliers, and whole organizational stakeholders [5], [11]. Today applications of IT and Computing are worthy and important in different areas and as a result Information System is applicable and noted with the following (but not limited to)-

- Information System led Marketing Systems.

- Information System led the Human Resource System.

- Information System led Financial Systems.

- Information System led Supply Chain Management Systems.

- Information System led Client Management System.

- Information System led Acquisition Systems.

Available online at https://dx.doi.org/10.19085/sijmd070701 


\section{Information Systems and Allied Nomenclature}

The field Information System is emerging rapidly throughout and applicable in different areas and as a result, it is also close/ known as-

- Information Management

- Information Systems

- Information Systems

- Information Systems and Management

- IT Management

- Management Information Systems, etc.

There are other nomenclature and fields which are also close with the Information Systems viz. Business Informatics, Business Information Systems, etc.

\section{Information Systems, Meaning and Components}

Information Systems are having different kind of components which are used in information processing and management. There are many fully electronic or digital or information systemcentric company viz. eBay, Amazon, Alibaba, Google, Facebook, etc. There are different technologies emerging in the field of Information Systems. Information Systems is a sociotechnical and organizational system that is dedicated to the information delivery mechanism not only computationally but also manually. The census tabular of Herman Hollerith invented in 1890 considered as the first large scale mechanical information systems [1], [8]. As far as socio-technical perspectives are concerned information system can be considered with the following four components-

- Task

- People

- Structure

- Technology

Computer-based Information Systems are lies on Computer and deals with people, and mainly computers. It is also referred to as Computer systems, though Computerized Information System is correct in the true sense. Information System is concentrated with the networks of hardware and software which is required for the organization and people regarding the collection, filter, process, creation and delivery of data and information. In an Information System, the thrust is provided on the following-

- Boundary

- Users

- Processors

- Storage

- Input and Outputs, etc.

Information Systems are worthy in operation support and management, decision support and making, etc. Information Systems purely depend on Information and Communication Technology and this helps in the business process and to the overall organizations. There are close connections with the Business Information Systems with Information Systems. However, both are dedicated to controlling the performance of the business process. 'Alter' an eminent expert in the field express that the work system is helpful in humans for the organizational services and Information Systems in this context is important and valuable. The capturing, transmitting, storing, retrieving, manipulating and displaying information in different media is important and valuable in Information Systems. Information Systems in interrelated to the Data System and close with the Communication Systems as well [3], [9].

Available online at https://dx.doi.org/10.19085/sijmd070701 
Silver et al. (1995) expressed that Information System includes software, hardware, data, people, and procedures. Zheng in another hand adds processes and environment, boundary, purpose, and interactions as part of the Information Systems [3], [16]. The largest Association of Computing i.e. ACM expressed Information Systems specialist focused on integrating IT Solutions and business processes to meet the information needs of business and other enterprises.

Information System is can be built not only with the software and hardware but also with other components and among these important are considered as follows-

- Hardware

- Software

- Data

- Procedure

- People

- Feedback.

These six components that must come together for an effective information system are important and should be provided with prime values (refer Fig: 4).

\section{Hardware-}

Hardware means the machinery and as far as computing is concerned it includes the equipment and tools that combine perfect hardware viz. Central Processing Units, Input and Output devices, storage devices, communication equipment, etc. Without Hardware there is no value of the software. In an Information Systems therefore hardware is a must and important.

\section{Software-}

Software is the computer programs and instructions to do the task and they follow the machine readable instruction and therefore software is a must for doing information related activities. As far as Information System is concerned without software nothing is possible.

\section{Data-}

An Information System normally processes the information and it includes the data. Therefore, data and information should be considered as important and valuable in respect of Information Systems designing and development. 


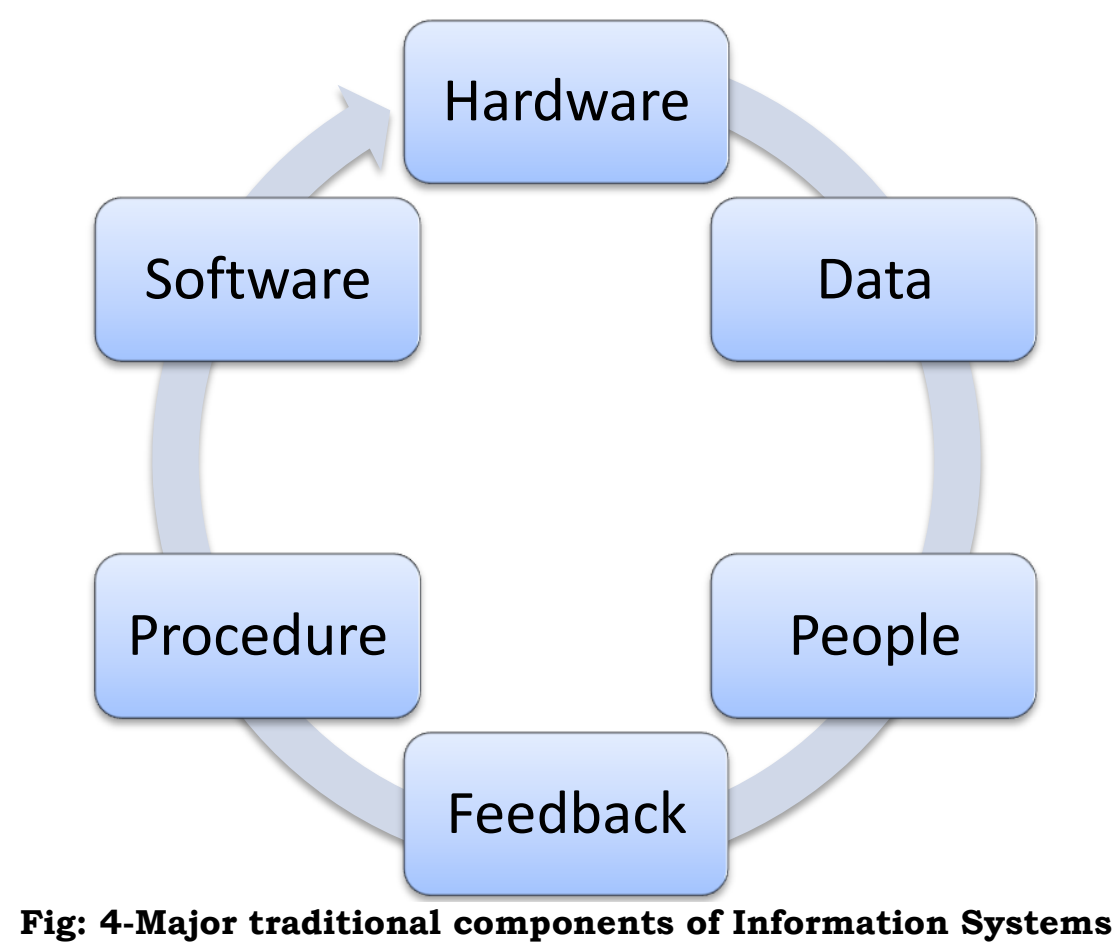

Procedures-

Procedures are the policies that govern the operation and in respect of Information Systems the as policies of software, hardware considered as valuable.

\section{People-}

Similar to the other systems and mechanisms in Information Systems also people should be considered as important. The designer and developer of the information systems are 'People' and on the other hand, Information Systems also dedicated to the people or human uses; therefore, Information Systems lie on people or human resources.

\section{Feedback-}

Information Systems is a valuable aspect in almost all the organizations and institutions and therefore for a proper and effective information systems apart from the components mentioned above 'Feedback' should be considered as important to reach its real goal and further improvement of the information systems from time to time [2], [17].

\section{Emerging Technologies in Information Systems}

Apart from the technologies and components mentioned above, there are other technologies also important in information systems designing, development and operation. In the recent past, such technologies are emerging and growing rapidly, and all these are worthy and important in the proper and effective Information Systems designing and operations to make organizations more digital and advanced. Some of these technologies and components are mentioned as under-

\section{Cloud Computing}

Cloud Computing is a kind of virtualization technology and it is responsible for the virtual availability of IT components and infrastructure, etc. Here the internet and similar 
infrastructure play an important role. Cloud Computing can be available with the following three types of models-

- Public Cloud Computing-Through the internet or public based systems this kind of Cloud Computing can be offered.

- Private Cloud Computing-The designing, development and build of such IT systems basically done within the concerned organization itself and depending upon need such can be availed.

- Hybrid Cloud Computing-The combination of Public Cloud Computing and Private Cloud Computing is responsible for making Hybrid Cloud Computing where privacy and ownerships are important issues.

Different kinds of IT products and services can be possible with Cloud Computing viz. software, storage and database, infrastructure, platform and systems, security and privacy, etc.

\section{Big Data and Analytics}

Data is important and needed in all the areas and sectors viz. Healthcare sector, Government sector, Private or public sector, horticulture, Management, Education, Agriculture, etc. Due to the growing volume of data various techniques are useful in Data Management. Big Data is evolved for Managing large amounts of data including Complex data management. And that's why it is called Big Data Management. Here lots of analytical tools are also used. The applications of Big Data in different sectors has resulted in much other domain-centric analytics viz.-

- Business Analytics (Big Data in different areas of Business, industries, organizations and Corporate).

- Health Analytics (Analytics in Healthcare, medicine, hospital management and allied segment, etc.),

- Retail Analytics (managing data and information in retail and marketing sectors), etc.

Apart from these Big Data and Analytics are widely applicable in other areas such as Transportation, Governance, Education, Commerce, Manufacturing, etc and apart from small companies big giant MNCs are Microsoft Corporation, Teradata Corporation, SAP, EMC, HP, Dell, etc are also engaged in Big Data and Analytics business for the development of modern and intelligent information systems [8], [13].

\section{Usability Engineering and HCI}

Usability Engineering is growing day by day, and there are other subjects also increasing in managing and designing interfaces of a different kind viz.-

- Human-Computer Interaction

- Man-Machine Interaction

- Human-Machine Interaction

- Usability Experience Design

- Human-Centered Designing

- User-Centered Designing etc

Usability Engineering is dedicated to modern Information Systems development as this is dedicated to the study, evaluation, designing, and development of interface of different electronic products viz. different kind of monitors (LCD, LED), websites, web portal, search engines, information retrieval system, ATM Systems, etc. In the building of sophisticated information systems to make more human-centered, instructiveness with proper utilizations 
Usability Engineering and $\mathrm{HCI}$ can be considered as important and valuable. There are different guidelines for building HCI based systems [14], [21].

\section{Artificial Intelligence}

Artificial Intelligence in short is called AI. It is a kind of simulation of human intelligence and that is enacted in the machines. The AI is helpful in making machines, programs like humans and also mimic their actions. The AI also supports the human brain viz. learning including problem-solving, etc, and able in taking actions for achieving a specific goal. Artificial Intelligence is also close to robotics. Artificial intelligence is a kind of human intelligence that can come from a device or a machine. It executes tasks or work. Artificial Intelligence with the following-

- Learning

- Reasoning, and

- Perception.

Here basic functions are considered as AI. This way, different kind of emerging technologies mentioned above can consider as worthy in developing organizations and institutions based information systems [7], [17].

\section{Types of Information Systems}

Information Systems in traditional and general context classified into following (but not limited to)-

- Transaction Processing Systems.

- Decision Support Systems.

- Knowledge Management Systems.

- Learning Management Systems.

- Executive Support Systems.

- Multimedia based Information Systems.

- Database Management Systems.

However, based on a recent study and emergence of IT and Computing Information Systems can also be classified by the periphery or territorial jurisdiction, manual and computational information systems, subject and discipline-specific information systems [4], [15], [16].

\section{Conclusion}

Information Systems are worthy and important in respect of delivery of information and making information ready institutions. Information is considered as one of the important tools for development and there are various ways to enhance and enrich the information infrastructure of an organization. Today subject-based information systems are also important in their respective role and development. Since information considers as important therefore various positions have also been created in the organizations viz. Chief Information Officer, Chief Technology Officer, Chief Information Security Officer and so on. Even IT Administrators, Systems Officers, Systems Administrators and others are also responsible for the development of the organization at par with international standards. Modern technologies are important and worthy in developing true, intelligent and sophisticated information systems development. Information Systems are therefore changing their concepts in components, types and users to make the world a global village truly.

Available online at https://dx.doi.org/10.19085/sijmd070701 


\section{Reference}

[1]. Adamuthe, A. C., Salunkhe, V. D., Patil, S. H., \& Thampi, G. T. (2015). Cloud Computing-A market Perspective and Research Directions. International Journal of Information Technology and Computer Science (IJITCS), 7(10), 42-53.

[2]. Al-Mamary, Y. H., Shamsuddin, A., \& Abdul Hamid, N. A. (2014). The meaning of management information systems and its role in telecommunication companies in Yemen. American Journal of Software Engineering, 2(2), 22-25.

[3]. Arch-int, S., \& Batanov, D. N. (2003). Development of industrial information systems on the Web using business components. Computers in Industry, 50(2), 231-250.

[4]. Brock, F. J., \& Dhillon, G. S. (2001). Managerial information, the basics. Journal of International Information Management, 10(2), 5.

[5]. Cram, W. A., Brohman, K., \& Gallupe, R. B. (2016). Information systems control: A review and framework for emerging information systems processes. Journal of the Association for Information Systems, 17(4), 2.

[6]. Ellis, C. A., \& Nutt, G. J. (1980). Office information systems and computer science. ACM Computing Surveys (CSUR), 12(1), 27-60.

[7]. Gillingham, P. (2011). Computer-based information systems and human service organisations: Emerging problems and future possibilities. Australian Social Work, 64(3), 299-312.

[8]. Ghose, R. (2001). Use of information technology for community empowerment: Transforming geographic information systems into community information systems. Transactions in GIS, 5(2), 141-163.

[9]. Holdstock, D. A. (1998). Basics of geographic information systems (GIS). Journal of Computing in Civil Engineering, 12(1), 1-4.

[10]. Lee, A. S., Thomas, M., \& Baskerville, R. L. (2015). Going back to basics in design science: from the information technology artifact to the information systems artifact. Information Systems Journal, 25(1), 5-21.

[11]. Maxwell, D., \& Watkins, B. (2003). Humanitarian information systems and emergencies in the Greater Horn of Africa: logical components and logical linkages. Disasters, 27(1), 72-90.

[12]. McCune, J. C. (1994). Information systems get back to basics. Management Review, 83(1), 54.

[13]. Mingers, J. C. (1995). Information and meaning: foundations for an intersubjective account.

[14]. Information Systems Journal, 5(4), 285-306.

[15]. Nunamaker Jr, J. F., Chen, M., \& Purdin, T. D. (1990). Systems development in information systems research. Journal of management information systems, 7(3), 89-106.

[16]. Paul, Prantosh Kumar, KL Dangwal, M Ghosh (2013). Information Systems \& Networks (ISN): Increasing Tools and Technological Application with Special Reference to Role as an Educational Tools. International Journal of Computer Sciences and Engineering Systems, 7 (2), 99-103

[17]. Paul, Prantosh Kumar, S Govindarajan, Dipak Chaterjee, R Bhatnagar (2013).information systems and Information Science: Overview emphasizing comparative study. SIT Journal of Management, 3(1) 336-341

[18]. Paul, Prantosh Kumar (2013). Interactive Design: the pillar of Modern Information Systems. Abhinav National Journal of Science and Technology, 2(3) 15-22.

[19]. Paul, Prantosh Kumar (2014). Information Systems and Different Domain, Functionalities and Types: A Conceptual Study. Pinnacle Mathematics \& Computer Science, 2(1), 01-05.

[20]. Paul, Prantosh Kumar, K. Kumar, D. Chatterjee, Minakshi Ghosh, K.S. Shivraj and Jhuma Ganguly. (2015). Agricultural Problems in India requiring solution through Agricultural Information Systems: Problems and Prospects in Developing Countries" in International Journal of Information Science and Computing, 2 (1), 33-40.

[21]. Robey, D. (1981). Computer information systems and organization structure. Communications of the ACM, 24(10), 679-687.

[22]. Stivers, B. P., \& Beard, L. H. (1987). Information systems: getting back to basics. Journal of Systems Management, 38(3), 35. 